\title{
THE STUDY OF SPECIAL VEHICLE BRAKING SYSTEM WORKING TEMPERATURES
}

\author{
Alin-Marian PUNCIOIU, Ioan VEDINAŞ, Valentin VÎNTURIŞ \\ Military Technical Academy, Bucharest, Romania, \\ alin_puncioiu@yahoo.com
}

\begin{abstract}
The paper presents the calculation of brake mechanism which involves determining the forces needed to be applied by the drive to reach the required braking moments at the wheel. The importance of braking system characteristics derived from how to active handle the vehicle and affect, in a decisive measure, valuing the performance of vehicle velocity and acceleration. Also, to assess the performance of braking mechanism, they aim to define the coefficient of efficiency and determining effectiveness characteristic depending on the thermal regime of work. Heating influences the dynamic performance of the vehicle brakes safely. To identify the evolution of brake heating they have become the realization of a measurement chain that was used for the measurement of all parameters during a long braking period. In the conclusions presented they show temperatures measured and how they could affect the determination of wear regime in operation.
\end{abstract}

\section{Keywords: braking system, heat, efficiency characteristic}

\section{Introduction}

The first vehicles fitted with engines used to produce the energy needed for wheeled engines that were already perfected over centuries of effort, increasing the power of internal combustion engines influencing the dynamic performance of the vehicle safely, so braking is a remarkable value as well as the critical component that can influence the growth index value of operating motor vehicles.

Special vehicles on wheels appeared as a necessity to bring them into objective compliance to fight in accordance with the conditions to complete the portions of the unarranged fields, with high speed, use of a vehicle for military purposes revolutionizing land forces mobility. The braking system is designed to reduce vehicle velocity faster or even to stop safely, to immobilize the stationary vehicle and to maintain a reasonable speed during downhill.

The braking system has to fulfill the following roles [4]:

- reducing speed to road safety set point or to stop the vehicle safely;

- immobilization of the vehicle on level ground or downhill including maximum slope approachable;

- the avoidance of excessive speeding car down long gradients.

To reduce vehicle speed forces opposing the movement have to be applied. As some drag has reduced effects (air resistance and rolling resistance) and resistance to acceleration, in case of breaking it becomes active power and it seems necessary that the vehicle has to be equipped with devices to achieve forces opposite movement. 
These forces are called braking forces; they must have sufficiently large values that can be set by the driver of the vehicle, as required. Braking forces are developed by the braking mechanisms that are part of the vehicle's braking system.

\section{The calculation of the brake with shoe and drum}

Calculation of brake mechanism involves determining the forces needed to be applied by the drive to reach the required braking moments at the wheel. It also aims to determine the operating arrangements for wear and temperature rise during braking phase.

There are many types of braking mechanisms with drum and shoe, as shown in Figure 1, classified in relation to the manner of support of the shoe and the direction of rotation [4].

The braking torque is created by friction to the drum [4]:

$M_{F}=F_{t b} r_{t}$

where $r_{t}$ is the radius at the friction lining of the drum.

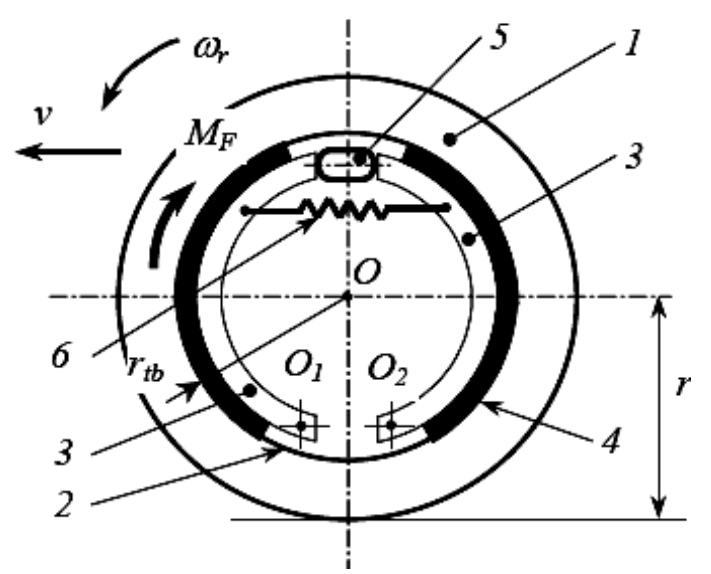

Figure 1: Scheme of a drum and shoe braking mechanism,

1-wheel; 2-drum; 3-shoe; 4-brake lining;

5-hydraulic cylinder; 6-return arc. [4]

If you take into account that the most intense braking occurs at limit of adhesion:

$F_{F}=m_{f} G_{r} \varphi$
- $\mathrm{m}_{\mathrm{F}}$ - Dynamic load factor of braked wheel;

- $\mathrm{G}_{\mathrm{r}}$ - weight on a wheel;

- $\varphi$ - coefficient of adhesion.

Taking into account that the maximum braking of a limit of adhesion occurs on the pavement, they use the following expression:

$M_{F 1}=\left(1+\varphi \frac{h_{g}}{b} \cos \alpha\right)$

which is the coefficient of dynamic loading to the entire front axle and $h_{g}$ is the height of the center of gravity of the vehicle, $b$ is the distance along the longitudinal axis of the vehicle of the raceway projection of the center of gravity and center of the contact patch with the ground wheel rear axle, and $\alpha$ is the angle of the slope;

$M_{F 2}=\left(1+\varphi \frac{h_{g}}{b} \cos \alpha\right)$

which is the coefficient of dynamic load of the entire rear axle, and $a$ is the distance along the axis of the raceway projection of the center of gravity and the center of the ground contact patch of the front axle. Finally, $\varphi=0.70 \ldots 0.75$ is the coefficient of adhesion-dry asphalt tire coupling characteristic.

\section{The coefficient of efficiency}

To assess the performance of the braking mechanism the brake efficiency coefficient relationship is defined [4]:

$$
E=\frac{M_{f}}{r_{t}\left(S_{1}+S_{2}\right)}
$$

The graphical representation of the effective coefficient relative to the shoe-drum friction coefficient is called effectiveness feature, as shown in Figure 2.

where: 


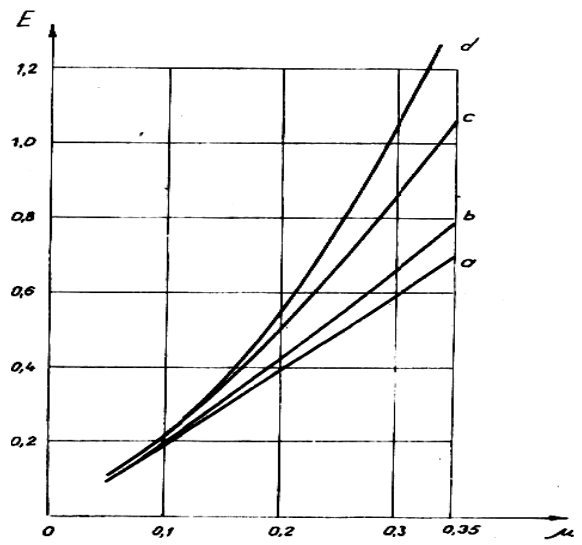

Figure 2: The efficiency characteristic of drum brake mechanisms; - simplex, with equal displacement of shoes; $b$ - simplex, with independent displacement of shoes; $c$-duplex;

$$
d \text {-servo [4] }
$$

For the studied vehicle braking system, presented in figure 3 , shoes are equally pressed by means of a hydraulic cylinder. It can write equality $\mathrm{S} 1=\mathrm{S} 2=\mathrm{S}$ and braking torque will be:

$M_{F}=\frac{2 \mu r_{t b}(a+c) c S}{c^{2}-(\mu e)^{2}}$

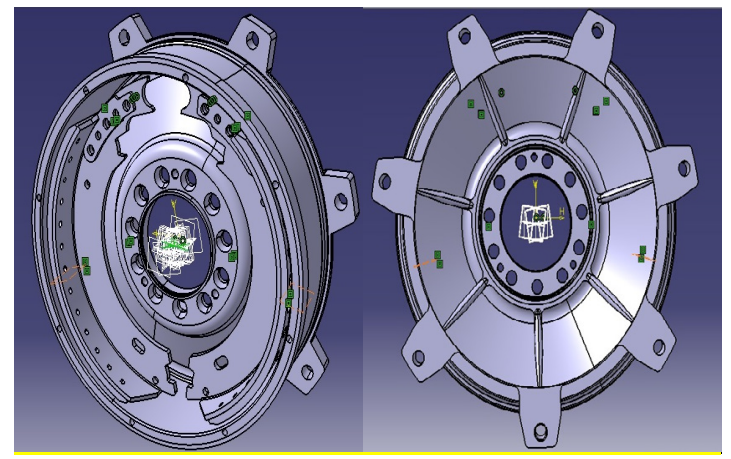

Figure 3: Special vehicle braking system with shoe and drum

The coefficient of efficiency will have the expression:

$$
E=\mu \frac{(a+c) c}{c^{2}-(\mu e)^{2}}
$$

where (for $\mathrm{a}=\mathrm{c}=\mathrm{e}$ and $\mu=0,3$ ) will provide the value $\mathrm{E}=0,66$.

\section{Brakes heating}

The amount of heat released in a second is determined by the relation [1]:

$$
Q=\frac{F_{f t} v_{a}}{427}=\frac{\mu p_{0} \Sigma A v_{a}}{427}[\mathrm{kcal} / \mathrm{s}]
$$

where: $v_{a}$ is the slip speed between the drum and the friction lining $\left(v_{a}=(\mathrm{V} / 3,6) \cdot\left(r_{t}\right.\right.$ $\left./ r_{r}\right) ; F_{f t}$ - the braking force acting on the drum $\left(\mathrm{F}_{\mathrm{ft}}=\mu p_{0} \Sigma \mathrm{A}\right) ; \Sigma \mathrm{A}-$ lining friction area; $p_{0}$ average pressure.

In relation to the manner of investigating, it was considered that for the precise control of phenomena pursued (speeds, moment, pressures, temperatures) is needed to measure them in multiple points.

In Figure 4 is shown how the vehicle instrumentation used to conduct experiments (how the data is retrieved): velocity, braking torque, the temperature of the shoe and drum temperature.

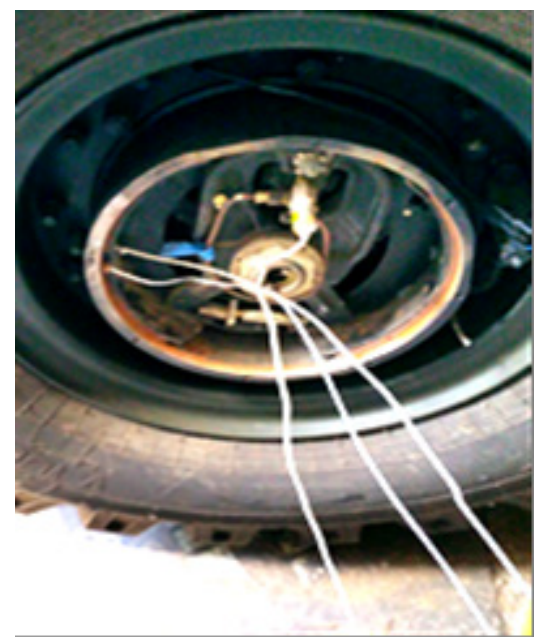

Figure 4: Installed sensors for taking the temperature of the brakes

The kinetic energy gained by the vehicle to maintain braking action turns on the one hand in heat (friction), energy which is then dissipated into the environment, and on the other hand is consumed for overcoming rolling and air resistance, which is always opposing the movement of the vehicle.

Carrying samples and data acquisition were done in several stages, with different braking moments.

In figures 5 and 6 are presented the evolution of temperatures during the conduct turnovers process which will 
continue to drive constant braking system with two different braking moments.

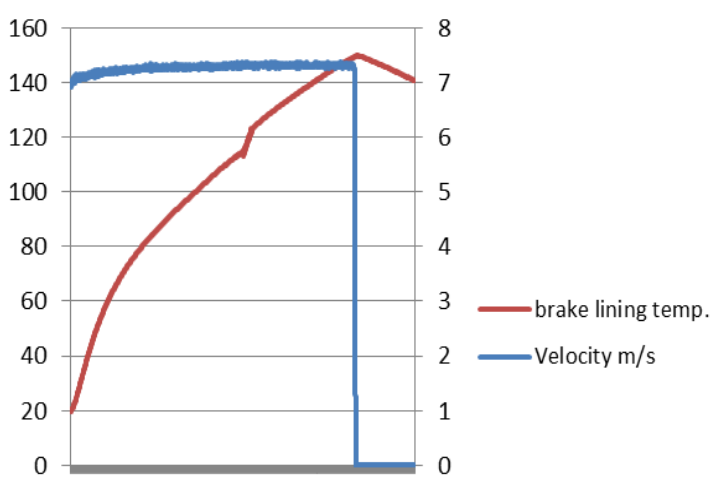

Figure 5: Braking temperature variation in time (low braking torque)

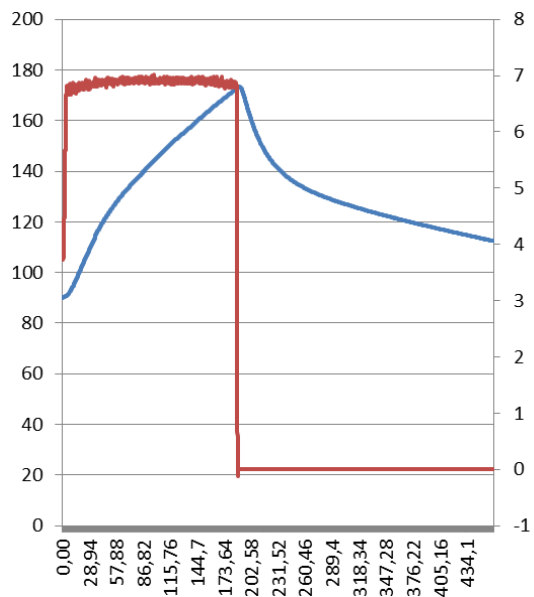

Figure 6: Braking temperature variation in time (high braking torque)

\section{Conclusions}

The procedures used in conducting experimental research proved adequate to achieve objectives. The tools used within the measurements allowed fully acceptable errors.

Measurements of temperatures led to the following conclusions:

1. when the vehicle is stopped and braking over reveals a rapid increase temperatures in the drum followed by high heat dissipation;

2. friction brake lining knows a rapid heating at the contact area as long as the generation of heat is made by applying shoe on the drum. However, once the shoe is withdrawn, the friction lining surface temperature decreases due to the process of convection and transmissibility of the shoe to the metallic element;

3 . at the contact area is achieved large increases in temperature during application of the shoe on the drum, the contact surface temperatures recorded were approx. 300 degrees. When checking thermal saturation temperature must not exceed-Seascale values that can change the properties of friction linings or drum. It is recommended to limit temperature not exceeding $300^{\circ} \mathrm{C}$, Seascale where test conditions correspond to those set out in Regulation no. 13 C.E.E. of the UNO[4];

4. Through an analysis of vehicle speed, there was a slight increase in its temperature rises, given the speed / engine output and braking torque remained constant. This feature effectively lead to the establishment so that the more the temperature is higher braking effectiveness is lower.

\section{Acknowledgements}

This paper has been financially supported within the project entitled "Horizon 2020 - Doctoral and Postdoctoral Studies: Promoting the National Interest through Excellence, Competitiveness and Responsibility in the Field of Romanian Fundamental and Applied Economic Research", contract number POSDRU/159/1.5/S/140106. This project is cofinanced by European Social Fund through Sectorial Operational Programme for Human Resources Development 2007-2013. Investing in people! 


\section{References}

[1] Frăţilă, Gh., Mărculescu, Gh., The braking systems of motor vehicles, Bucharest, Technical Publishing House, 1986.

[2] Limpert, R., Brake design and safety, third ed., SAE International, Warrendale, 2011.

[3] Marinescu, M., Modern Solutions in Vehicle Manufacturing., Bucharest, Military Technical Academy Publishing House, 2002.

[4] Marinescu, M., Theory, calculation and construction of armored personnel carrier. Bucharest, Military Technical Academy Publishing House, 2006.

[5] Puncioiu, A., Truţă, M., Determine the parameters of the braking capacity of the special vehicles braking systems., Review of the Air Force Academy, No 3, pp. 83-88, 2014. 